\title{
Observational Study of the Clinical Characteristics and Short-Term Outcomes of Kidney Transplant Recipients Diagnosed With COVID-19 Infection (SARS-CoV-2) Requiring Hospitalization in New Orleans
}

\author{
Sixto Giusti, MD, FASN, ${ }^{1,2}$ Shai Chazin, BS, ${ }^{2}$ Pradeep Vaitla, MD, ${ }^{3}$ Kofi Atiemo, MD, ${ }^{2}$ Mohammad Atari, MD, ${ }^{1}$ \\ Anil Paramesh, MD, MBA, FACS, ${ }^{2}$ Hoonbae Jeon, MD, FACS, ${ }^{2}$ Aldo Torres-Ortiz, MD, ${ }^{4}$ Ravi Thimmisetty, MD, ${ }^{5}$ \\ Jorge Garces, MD, FASN ${ }^{5,6}$ \\ ${ }^{1}$ Department of Medicine, Section of Nephrology and Hypertension, Tulane University School of Medicine, New Orleans, LA ${ }^{2}$ Department of \\ Surgery, Kidney and Pancreas Transplant Program, Tulane University School of Medicine, New Orleans, LA ${ }^{3}$ Department of Medicine, \\ Section of Nephrology and Transplant, University of Mississippi Medical Center, Jackson, MS ${ }^{4}$ Department of Internal Medicine, Ochsner \\ Clinic Foundation, New Orleans, LA ${ }^{5}$ Multi-Organ Transplant Institute, Ochsner Clinic Foundation, New Orleans, LA ${ }^{6}$ The University of \\ Queensland Faculty of Medicine, Ochsner Clinic Foundation, New Orleans, LA
}

Background: Kidney transplant recipients are at increased risk of severe disease and death caused by coronavirus disease 2019 (COVID-19) infection. The role of immunosuppressive medications in the clinical presentation, disease course, and outcomes is not well understood.

Methods: We analyzed kidney transplant recipients diagnosed with COVID-19 and requiring hospitalization during the initial infection surge at 2 large transplant centers in New Orleans, Louisiana, between February 1, 2020 and April 30, 2020. Patient presentation, clinical course, kidney transplant function, and postdischarge details are included in this analysis.

Results: Twenty-three kidney transplant recipients hospitalized with COVID-19 were included in the study. The majority of patients were Black (95.7\%). Diabetes, hypertension, and obesity were present in more than $50 \%$ of the patients. The most common presenting symptom was fever, present in $52.2 \%$ of patients. All patients were managed with reduction in immunosuppression. Patients received azithromycin (60.9\%), hydroxychloroquine (47.8\%), remdesivir (8.7\%), and intravenous methylprednisolone pulse (8.7\%). The average length of stay was 4.5 days (range, 2-18 days). In this study population, $73.9 \%$ of the patients sustained acute kidney injury, with an average peak serum creatinine of $3.81 \mathrm{mg} / \mathrm{dL}$. Twenty-six percent of the patients required renal replacement therapy. Seventy-seven percent of patients developed proteinuria (at least 1+ proteinuria on urinalysis). Of the patients in this population who required mechanical ventilation (39.1\%), 77.8\% died. Overall, 30.4\% of patients died of COVID-19-related complications during admission. Of the 16 patients discharged, the average serum creatinine at discharge was $2.09 \mathrm{mg} / \mathrm{dL}$ compared with an average preadmission serum creatinine of $1.8 \mathrm{mg} / \mathrm{dL}$.

Conclusion: During the initial COVID-19 infection surge in New Orleans, we noted that kidney transplant recipients had initial symptoms similar to the general population. However, we recorded a higher incidence of acute kidney injury and death compared to nontransplant patients. Patients who required mechanical ventilation had a high mortality rate. Black patients are overrepresented in our study.

Keywords: Acute kidney injury, COVID-19, immunosuppression, mortality, transplant recipients

Address correspondence to Sixto Giusti, MD, FASN, Department of Medicine, Section of Nephrology and Hypertension, Tulane University School of Medicine, 1415 Tulane Ave., New Orleans, LA 70112. Tel: (504) 988-1457. Email: sgiustitorres@tulane.edu

\section{INTRODUCTION}

According to data from the Centers for Disease Control and Prevention (CDC), the number of coronavirus disease 2019 (COVID-19) cases in the United States had reached 8.68 million as of October 27, 2020. The overall case fatality rate was $3 \%$, with in-hospital mortality of $14.2 \% .^{1,2}$ Cases of transplant patients infected with severe acute respiratory syndrome coronavirus 2 (SARS-CoV-2), the virus that causes COVID-19, have reported mortality rates ranging from $18 \%$ to $32 \% .^{3-7}$ The increased mortality is likely related to the 
Table 1. Demographics and Baseline Characteristics, $n=23$

\begin{tabular}{|c|c|}
\hline Variable & Value \\
\hline Age, years, mean (range) & $52.9(38-80)$ \\
\hline Male & $16(69.6)$ \\
\hline Black & $22(95.7)$ \\
\hline History of hypertension & $20(87.0)$ \\
\hline History of diabetes & $12(52.2)$ \\
\hline Obesity (BMI > $\left.30 \mathrm{~kg} / \mathrm{m}^{2}\right)$ & $12(52.2)$ \\
\hline History of malignancy & $3(13.0)$ \\
\hline Time posttransplant to admission, years, median (IQR) & $7(10.6)$ \\
\hline \multicolumn{2}{|l|}{ Type of transplant } \\
\hline Kidney alone & $18(78.3)$ \\
\hline Kidney and pancreas & $3(13.0)$ \\
\hline Kidney and liver & $2(8.7)$ \\
\hline \multicolumn{2}{|l|}{ Maintenance immunosuppression } \\
\hline Calcineurin inhibitor plus antiproliferative agent ${ }^{\mathrm{a}}$ & $18(78.3)$ \\
\hline Low-dose prednisone & $17(73.9)$ \\
\hline \multicolumn{2}{|l|}{ Chronic kidney disease stage } \\
\hline 2 & $5(21.7)$ \\
\hline $3 a$ & $8(34.8)$ \\
\hline $3 b$ & $7(30.4)$ \\
\hline 4 & $3(13.0)$ \\
\hline Baseline serum creatinine, mg/dL, mean (range) & $1.8(1.0-2.8)$ \\
\hline
\end{tabular}

${ }^{a}$ Calcineurin inhibitors were either tacrolimus or cyclosporine. Antiproliferative agents were either mycophenolate mofetil or azathioprine. Note: Data are presented as $\mathrm{n}(\%)$ unless otherwise indicated.

BMI, body mass index.

comorbidities hypertension, diabetes, and chronic kidney disease (CKD) among transplant recipients, which are associated with higher rates of mortality among patients with COVID-19 infection. ${ }^{4,8}$ Furthermore, Black patients are at higher risk for severe COVID-19 infection and death compared to White patients. . $^{9,10}$

The role immunosuppression plays in disease presentation, clinical course, and outcomes is currently under investigation. Reports suggest that reducing immunosuppressive medications in COVID-19-infected transplant recipients is indicated, particularly antiproliferative agents and/or calcineurin inhibitors. ${ }^{3-7,11-15}$ Additionally, atypical presentations among transplant recipients, such as being less likely to present with fever, possibly reflect immunologic changes in patients taking immunosuppressive medications. ${ }^{16}$

We report the clinical presentations and short-term outcomes of COVID-19-infected kidney transplant recipients during the initial COVID-19 infection surge in New Orleans, Louisiana.

\section{METHODS}

We analyzed COVID-19-infected kidney transplant recipients admitted at 2 transplant centers in New Orleans between February 1, 2020 and April 30, 2020. Inclusion criteria were kidney transplant recipients with a functioning allograft who were $>18$ years and who demonstrated polymerase chain reaction positivity for SARS-CoV-2 infection.
Patients with incomplete medical records were excluded. We analyzed patient demographics, clinical course, kidney transplant function, and postdischarge follow-up to a maximum of 60 days. The study was approved by the Tulane University School of Medicine Institutional Review Board (IRB), and the requirements to obtain informed consent were waived in accordance with 45 CFR 46.116 (d). The IRB did not identify any ethical concerns.

\section{RESULTS \\ Demographics and Baseline Characteristics}

Twenty-three patients admitted (11 at one hospital, 12 at the other) with COVID-19 infection were included in this study. The average patient age was 52.9 years, and $95.7 \%$ were Black (Table 1). Regarding medical history, $52.2 \%$ had a history of diabetes and were obese (body mass index $\geq 30 \mathrm{~kg} / \mathrm{m}^{2}$ ), and $87 \%$ had a history of hypertension. The median posttransplant time at the time of hospitalization was 7 years $(\mathrm{IQR}=10.6)$. Etiologies of native kidney disease varied and most commonly included diabetes and hypertension. In our population, $78.3 \%$ of patients were on a combination of calcineurin inhibitor (tacrolimus/ cyclosporine) and antiproliferative agent (mycophenolate mofetil/azathioprine); $73.9 \%$ of patients were on maintenance low-dose prednisone. The average baseline serum creatinine (based on values up to 3 months before admission) was $1.8 \mathrm{mg} / \mathrm{dL}$. 
Table 2. Presentation, Hospital Course, and Outcomes, $\mathbf{n}=\mathbf{2 3}$

\begin{tabular}{|c|c|}
\hline Variable & Value \\
\hline Symptom duration prior to admission, days, mean (range) & $6.1(1-17)$ \\
\hline \multicolumn{2}{|l|}{ Presenting symptoms } \\
\hline Fever & $12(52.2)$ \\
\hline Cough & $11(47.8)$ \\
\hline Dyspnea & $10(43.5)$ \\
\hline Weakness & $6(26.1)$ \\
\hline Diarrhea & $5(21.7)$ \\
\hline Nausea & $5(21.7)$ \\
\hline Myalgias & $4(17.4)$ \\
\hline Vomiting & $3(13.0)$ \\
\hline Altered mental status & $2(8.7)$ \\
\hline Lightheadedness & $2(8.7)$ \\
\hline Length of stay, days, mean (range) & $4.5(2-18)$ \\
\hline Community-acquired infection & $22(95.7)$ \\
\hline \multicolumn{2}{|l|}{ Treatment } \\
\hline Reduction in immunosuppression & $23(100)$ \\
\hline Azithromycin & $14(60.9)$ \\
\hline Hydroxychloroquine & $11(47.8)$ \\
\hline Remdesivir & $2(8.7)$ \\
\hline Methylprednisolone pulse & $2(8.7)$ \\
\hline Lung infiltrates on initial chest x-ray & $15(65.2)$ \\
\hline Venous thromboembolic episode & $3(13.0)$ \\
\hline Required mechanical ventilation & $9(39.1)$ \\
\hline Mortality of mechanical ventilation subgroup & $7(77.8)$ \\
\hline Acute kidney injury & $17(73.9)$ \\
\hline Mortality of acute kidney injury subgroup & $6(35.3)$ \\
\hline Peak serum creatinine, mg/dL, mean (range) & $3.81(0.8-1.4)$ \\
\hline Required renal replacement therapy & $6(26.1)$ \\
\hline Received diuretics during admission & $5(21.7)$ \\
\hline Received ACE/ARB during admission & $2(8.7)$ \\
\hline Serum creatinine at discharge, mg/dL, mean (range) & $2.09(0.9-5.4)$ \\
\hline Died from COVID-19 complications & $7(30.4)$ \\
\hline
\end{tabular}

Note: Data are presented as $\mathrm{n}(\%)$ unless otherwise indicated.

ACE, angiotensin-converting enzyme; ARB, angiotensin receptor blocker; COVID-19, coronavirus disease 2019.

\section{Hospital Course and Outcomes}

Presenting symptoms of COVID-19 are shown in Table 2 and included fever, cough, and dyspnea. The most common presenting symptom was fever, present in $52.2 \%$ of patients. On average, patients had symptoms for 6.1 days before hospitalization, and $95.7 \%$ of patients acquired infection in a community setting. The average length of stay was 4.5 days.

All patients were treated initially with a reduction in immunosuppression, most commonly by reducing the dose of antiproliferative agent. Patients received azithromycin (60.9\%), hydroxychloroquine $(47.8 \%)$, remdesivir $(8.7 \%)$, and intravenous methylprednisolone pulse (8.7\%). On ini- tial chest x-ray, $65.2 \%$ of the patients had lung infiltrates. Mechanical ventilation was required for 9 (39.1\%) patients; $77.8 \%$ of patients who required mechanical ventilation died during admission. All patients requiring mechanical ventilation had acute kidney injury (AKI). Venous thromboembolic episodes occurred in $13.0 \%$ of patients.

Inflammatory markers were measured at the time of admission, and the average values are presented in Table 3. Interleukin-6 levels were available in 3 patients, with an average value of $16.5 \mathrm{pg} / \mathrm{mL}$. Average white blood cell count upon admission was $6.76 \mathrm{k} / \mu \mathrm{L}$, while hemoglobin average upon admission was $12.1 \mathrm{~g} / \mathrm{dL}$, and platelet count was $214.9 \mathrm{k} / \mu \mathrm{L}$. 
Table 3. Laboratory Values on Admission

\begin{tabular}{lcc}
\hline \multicolumn{1}{c}{ Test } & Mean & Normal Range \\
\hline C-reactive protein, $\mathrm{n}=21$ & $61 \mathrm{mg} / \mathrm{L}$ & $<10 \mathrm{mg} / \mathrm{dL}$ \\
Erythrocyte sedimentation rate, $\mathrm{n}=8$ & $68 \mathrm{~mm} / \mathrm{h}$ & Males: $0-22 \mathrm{~mm} / \mathrm{h}$ \\
& & Females: $0-29 \mathrm{~mm} / \mathrm{h}$ \\
Ferritin, $\mathrm{n}=21$ & $1,609.4 \mathrm{ng} / \mathrm{mL}$ & $\mathrm{Males:} 20-250 \mathrm{ng} / \mathrm{mL}$ \\
& & Females: $10-120 \mathrm{ng} / \mathrm{mL}$ \\
Procalcitonin, $\mathrm{n}=19$ & $1.9855 \mathrm{ng} / \mathrm{mL}$ & $0.10-0.49 \mathrm{ng} / \mathrm{mL}$ \\
Lactate dehydrogenase, $\mathrm{n}=21$ & $310.5 \mathrm{U} / \mathrm{L}$ & $140-280 \mathrm{U} / \mathrm{L}$ \\
Interleukin $6, \mathrm{n}=3$ & $16.5 \mathrm{pg} / \mathrm{mL}$ & $0-16.4 \mathrm{pg} / \mathrm{mL}$ \\
White blood cell count, $\mathrm{n}=23$ & $6.76 \mathrm{k} / \mu \mathrm{L}$ & $5-10 \mathrm{k} / \mu \mathrm{L}$ \\
Hemoglobin, $\mathrm{n}=22$ & $12.1 \mathrm{~g} / \mathrm{dL}$ & $\mathrm{Males:} 13.8-17.2 \mathrm{~g} / \mathrm{dL}$ \\
Platelet count, $\mathrm{n}=22$ & & Females: $12.1-15.1 \mathrm{~g} / \mathrm{dL}$ \\
Spot urine protein to creatinine ratio, $\mathrm{n}=6$ & $214.9 \mathrm{k} / \mu \mathrm{L}$ & $140-400 \mathrm{k} / \mu \mathrm{L}$
\end{tabular}

Seventeen patients (73.9\%) developed AKI, with an average peak serum creatinine of $3.81 \mathrm{mg} / \mathrm{dL}$. Of patients with AKI, 35.3\% (6/17) died. Renal replacement therapy was required for $26.1 \%$ of admitted patients. During hospital admission, $21.7 \%$ of patients received diuretics. Prior to admission, $39 \%$ of patients were on angiotensin-converting enzyme inhibitors or angiotensin receptor blockers, while only $8.7 \%$ received them during admission. Urinalysis showed that $77 \%$ percent of patients had at least +1 protein, and the average urine protein creatinine ratio during admission was $1.08 \mathrm{~g} / \mathrm{g}$. During admission, $30.4 \%$ of patients died of COVID-19-related complications. In terms of allograft function post-COVID-19 admission, average serum creatinine was $2.09 \mathrm{mg} / \mathrm{dL}$ at discharge compared to an average baseline serum creatinine before admission of $1.8 \mathrm{mg} / \mathrm{dL}$. All patients with baseline stage 4 CKD (13.0\%) died.

\section{DISCUSSION \\ COVID-19 Infection Effects on the Kidney}

AKI has emerged as a distinct feature of COVID-19 infection, with the incidence in hospitalized patients ranging from $22 \%$ to $57 \%$ in large US samples. ${ }^{17-19}$ The incidence of severe (stage 3) AKI among patients hospitalized with COVID-19 was higher when compared to COVID-19 negative controls and a historic cohort. ${ }^{19}$ Cheng et al reported a mortality rate of $72 \%$ in patients with AKI and COVID-19 compared to $14 \%$ mortality in patients without AKI. ${ }^{20}$ Lee et al reported that only $30 \%$ of patients with AKI and COVID19 recovered baseline kidney function and were discharged alive. $^{21}$

Biopsy findings in patients with COVID-19 and AKI have ranged from acute tubular necrosis, to minimal change disease, to collapsing focal segmental glomerulosclerosis. ${ }^{22-24}$ Whether these findings are a consequence of severe systemic disease or direct cytotoxic effects on the kidney is not yet known. However, an autopsy series of 22 patients who died from COVID-19 showed renal tropism of SARSCoV-2 with preferential targeting of glomerular cells. ${ }^{25}$ These findings are consistent with past evidence of angiotensin- converting enzyme 2 expression in human kidneys, which is known to be the primary receptor for SARS-CoV-2 tissue invasion. ${ }^{26}$

Our results show similar findings of high rates of AKI among COVID-19-infected individuals (73.9\%), with a mortality rate of $35.3 \%$ among patients with AKI. These findings point to the possibility of an increased risk of AKI among transplant recipients that could contribute to higher death rates. However, no causal inferences can be made from our sample, and whether our high rates of $A K I$ reflect direct kidney targeting by SARS-CoV-2 or a manifestation of systemic disease remains unclear.

\section{COVID-19 Infection in Patients With Kidney Disease}

Nearly 750,000 people in the United States have endstage renal disease. ${ }^{27}$ The CDC estimates that $15 \%$ of US adults have CKD. ${ }^{28}$ Patients with kidney disease often have other comorbidities, putting them at increased risk for more severe COVID-19 infection. An early analysis of COVID19-infected patients found that patients with CKD represented $9 \%$ and $12 \%$ of hospitalized non-intensive care unit (ICU) and ICU admissions, respectively. ${ }^{29}$ Furthermore, a meta-analysis of 4 studies that included 1,389 COVID-19infected patients demonstrated a higher risk of severe infection in CKD patients (odds ratio=3.03, 95\% Cl 1.09-8.47). ${ }^{30}$ Hemodialysis patients may present atypically (less likely to present with fever, cough, and fatigue compared to nondialysis controls) but have a higher risk of death compared to nondialysis patients with COVID-19. ${ }^{31,32}$

While our sample did not include patients on dialysis at baseline, we observed a mortality rate of $100 \%$ in patients with stage $4 \mathrm{CKD}, 28.6 \%$ in patients with stage $3 \mathrm{~b} C K D$, and $12.56 \%$ in patients with stage $3 a$ CKD.

\section{COVID-19 Infection in Kidney Transplant Recipients}

Transplant recipients represent a unique patient population in which the role of immunosuppression is unclear. On the one hand, chronic immunosuppression may dampen the 
hyperinflammatory state that is thought to be a substantial contributor to organ injury in COVID-19 infection. On the other hand, a diminished $T$ cell population may increase the burden of virus, leading to more severe infection. Nevertheless, transplant recipients appear to be at higher risk of mortality, with in-hospital mortality rates ranging from $18 \%$ to $32 \%$ compared to $14.2 \%$ for the general population. $2,3-7$ This increased risk is confirmed by our study, which showed a $30.4 \%$ in-hospital mortality.

Similar to patients on hemodialysis, atypical presentations among transplant recipients compared to nontransplant patients have been reported in observational studies, including more patients with gastrointestinal (Gl) symptoms (eg, vomiting) and fewer with fever. ${ }^{16,33}$

In a literature review of GI manifestations of COVID-19, Abbasinia et al noted diarrhea and vomiting were the most frequently observed $\mathrm{Gl}$ symptoms, with rates ranging from $2.0 \%$ to $33.7 \%$ and $1.0 \%$ to $11.1 \%$, respectively. ${ }^{34}$ Rates of diarrhea and vomiting in our sample are close to these observations.

Fever was the most frequently observed presenting symptom in our sample. Huang et al observed a fever rate of $80 \%$ in their sample of 41 patients in Wuhan, China, with fever defined as a temperature $>38{ }^{\circ} \mathrm{C} .{ }^{35}$ Conversely, Richardson et al observed a fever rate of $30.7 \%$ in their report on presenting characteristics and outcomes of hospitalized patients with COVID-19 in New York City. ${ }^{17}$ The rate of fever in our sample falls in the middle of these observations, possibly indicating more similarities than differences in the presenting symptoms between transplant and nontransplant patients. Further studies are warranted.

\section{COVID-19 Infection Effect on Black Patients}

Black patients appear to be particularly at higher risk for COVID-19 exposure and severe outcomes compared to White patients. In our study, 95.7\% (22/23) of patients were Black. In contrast, from a total of 2,562 actively followed posttransplant patients in both participating centers, only $49 \%$ identified as Black. We found an in-hospital mortality rate of $27.2 \%$ among Black patients with COVID-19 (6/22 Black patients died) compared to $14.2 \%$ nationally. Price-Haywood and colleagues observed similar racial differences in their study of characteristics and clinical outcomes between racial categories. ${ }^{10}$ Black and female patients represented the majority of COVID-19-positive patients, and $80 \%$ of patients who received critical care or mechanical ventilation were Black. Furthermore, Blacks were overrepresented among all patients who died in the hospital (70.6\%) although in-hospital mortality was similar between racial categories after adjustment for differences in socioeconomic and clinical characteristics on admission. ${ }^{10}$ Similar findings were noted in a study published by Gold et al in which $80 \%$ of hospitalized patients with COVID-19 in Georgia were Black. ${ }^{36}$

The observed differences in outcomes are likely multifactorial in origin. Price-Haywood et al found a higher prevalence of obesity, diabetes, hypertension, and CKD at baseline in Black patients compared to White patients. ${ }^{10}$ Socioeconomic factors such as type of job or housing density may have prevented social distancing, and racial differences in access to medical care can hinder adequate control of chronic medical conditions. ${ }^{37}$ All of these factors may contribute to the poor outcomes observed in Black patients with COVID-19.

\section{CONCLUSION}

During the initial infection surge in New Orleans, transplant recipients with COVID-19 appeared to present with similar symptoms as nontransplant patients but had an increased risk for $\mathrm{AKI}$ and death compared to the general population (ie, in-hospital mortality rate of $14.2 \%$ ). Most of the patients were Black. Patients sustaining kidney injury and requiring mechanical ventilation had the worst outcomes. Kidney function did not return to baseline at discharge in patients sustaining AKI. Specific treatment regimens for transplant recipients remain to be determined.

\section{ACKNOWLEDGMENTS}

The authors have no financial or proprietary interest in the subject matter of this article.

\section{REFERENCES}

1. Coronavirus disease 2019 (COVID-19) in the U.S. Centers for Disease Control and Prevention. 2020. Accessed September 18, 2020. covid.cdc.gov/covid-data-tracker/\#datatracker-home

2. Laboratory-confirmed COVID-19-associated hospitalizations. Centers for Disease Control and Prevention. 2020. Accessed September 18, 2020. gis.cdc.gov/grasp/COVIDNet/COVID19_5.html

3. Alberici F, Delbarba E, Manenti C, et al. A single center observational study of the clinical characteristics and short-term outcome of 20 kidney transplant patients admitted for SARS-CoV2 pneumonia. Kidney Int. 2020;97(6):1083-1088. doi: 10.1016/j.kint.2020.04.002

4. Chaudhry ZS, Williams JD, Vahia A, et al. Clinical characteristics and outcomes of COVID-19 in solid organ transplant recipients: a cohort study. Am J Transplant. 2020;20(11):3051-3060. doi: 10.1111/ajt.16188

5. Cravedi P, Mothi SS, Azzi Y, et al. COVID-19 and kidney transplantation: results from the TANGO International Transplant Consortium. Am J Transplant. 2020;20(11):3140-3148. doi: 10.1111/ajt.16185

6. Pereira MR, Mohan S, Cohen DJ, et al. COVID-19 in solid organ transplant recipients: initial report from the US epicenter. Am J Transplant. 2020;20(7):1800-1808. doi: 10.1111/ajt.15941

7. Lubetzky M, Aull MJ, Craig-Schapiro R, et al. Kidney allograft recipients, immunosuppression, and coronavirus disease-2019: a report of consecutive cases from a New York City transplant center. Nephrol Dial Transplant. 2020;35(7):1250-1261. doi: $10.1093 /$ ndt/gfaa154

8. Zhou F, Yu T, Du R, et al. Clinical course and risk factors for mortality of adult inpatients with COVID-19 in Wuhan, China: a retrospective cohort study. Lancet. 2020;395(10229): 1054-1062. doi: 10.1016/S0140-6736(20)30566-3

9. Yehia BR, Winegar A, Fogel $R$, et al. Association of race with mortality among patients hospitalized with coronavirus disease 2019 (COVID-19) at 92 US hospitals. JAMA Netw Open. 2020;3(8):e2018039.

doi: 10.1001/jamanetworkopen.2020.18039

10. Price-Haywood EG, Burton J, Fort D, Seoane L. Hospitalization and mortality among black patients and white patients with Covid-19. N Engl J Med. 2020;382(26):2534-2543. doi: 10.1056/NEJMsa2011686

11. Banerjee D, Popoola J, Shah S, Ster IC, Quan V, Phanish M. COVID-19 infection in kidney transplant recipients. Kidney Int. 2020;97(6):1076-1082. doi: 10.1016/j.kint.2020.03.018 
12. Johnson KM, Belfer JJ, Peterson GR, Boelkins MR, Dumkow LE. Managing COVID-19 in renal transplant recipients: a review of recent literature and case supporting corticosteroid-sparing immunosuppression. Pharmacotherapy. 2020;40(6):517-524. doi: 10.1002/phar.2410

13. Columbia University Kidney Transplant Program. Early description of coronavirus 2019 disease in kidney transplant recipients in New York. J Am Soc Nephrol. 2020;31(6):1150-1156. doi: 10.1681/ASN.2020030375

14. Husain SA, Dube G, Morris $H$, et al. Early outcomes of outpatient management of kidney transplant recipients with coronavirus disease 2019. Clin J Am Soc Nephrol. 2020;15(8):1174-1178. doi: 10.2215/CJN.05170420

15. Nair V, Jandovitz N, Hirsch JS, et al. COVID-19 in kidney transplant recipients. Am J Transplant. 2020;20(7):1819-1825. doi: 10.1111/ajt.15967

16. Akalin E, Azzi Y, Bartash R, et al. Covid-19 and kidney transplantation. N Engl J Med. 2020;382(25):2475-2477. doi: 10.1056/NEJMc2011117

17. Richardson S, Hirsch JS, Narasimhan M, et al. Presenting characteristics, comorbidities, and outcomes among 5700 patients hospitalized with COVID-19 in the New York City area. JAMA. 2020;323(20):2052-2059. doi: 10.1001/jama.2020.6775

18. Mohamed MMB, Lukitsch I, Torres-Ortiz AE, et al. Acute kidney injury associated with coronavirus disease 2019 in urban New Orleans. Kidney360. 2020;1(7):614-622. doi: $10.34067 / \mathrm{kid} .0002652020$

19. Fisher $M$, Neugarten J, Bellin $E$, et al. AKI in hospitalized patients with and without COVID-19: a comparison study. J Am Soc Nephrol. 2020;31(9):2145-2157. doi: 10.1681/ASN.2020040509

20. Cheng $Y$, Luo $R$, Wang $X$, et al. The incidence, risk factors, and prognosis of acute kidney injury in adult patients with coronavirus disease 2019. Clin J Am Soc Nephrol. 2020;15(10):1394-1402. doi: 10.2215/CJN.04650420

21. Lee JR, Silberzweig J, Akchurin O, et al. Characteristics of acute kidney injury in hospitalized COVID-19 patients in an urban academic medical center. Clin J Am Soc Nephrol. 2021;16(2):284-286. doi: 10.2215/CJN.07440520

22. Sharma P, Uppal NN, Wanchoo R, et al. COVID-19-associated kidney injury: a case series of kidney biopsy findings. J Am Soc Nephrol. 2020;31(9):1948-1958. doi: 10.1681/ASN.2020050699

23. Kudose $S$, Batal I, Santoriello D, et al. Kidney biopsy findings in patients with COVID-19. J Am Soc Nephrol. 2020;31(9):1959-1968. doi: 10.1681/ASN.2020060802

24. Wu H, Larsen CP, Hernandez-Arroyo CF, et al. AKI and collapsing glomerulopathy associated with COVID-19 and Apol1 high-risk genotype. J Am Soc Nephrol. 2020;31(8):1688-1695. doi: 10.1681/ASN.2020050558
25. Puelles VG, Lütgehetmann M, Lindenmeyer MT, et al. Multiorgan and renal tropism of SARS-CoV-2. N Engl J Med. 2020;383(6):590-592. doi: 10.1056/NEJMc2011400

26. Mizuiri S, Ohashi Y. ACE and ACE2 in kidney disease. World J Nephrol. 2015;4(1):74-82. doi: 10.5527/wjn.v4.i1.74

27. Saran R, Robinson B, Abbott KC, et al. US Renal Data System 2019 Annual Data Report: epidemiology of kidney disease in the United States. Am J Kidney Dis. 2020;75(1 Suppl 1):A6-A7. doi: 10.1053/j.ajkd.2019.09.003

28. Centers for Disease Control and Prevention. Chronic kidney disease in the United States, 2019. Accessed September 22, 2021. www.cdc.gov/kidneydisease/pdf/2019_NationalChronic-Kidney-Disease-Fact-Sheet.pdf

29. CDC COVID-19 Response Team. Preliminary estimates of the prevalence of selected underlying health conditions among patients with coronavirus disease 2019 - United States, February 12-March 28, 2020. MMWR Morb Mortal Wkly Rep. 2020;69(13):382-386. doi: 10.15585/mmwr.mm6913e2

30. Henry BM, Lippi G. Chronic kidney disease is associated with severe coronavirus disease 2019 (COVID-19) infection. Int Urol Nephrol. 2020;52(6):1193-1194. doi: 10.1007/s11255-020-02451-9

31. Wu J, Li J, Zhu G, et al. Clinical features of maintenance hemodialysis patients with 2019 novel coronavirus-infected pneumonia in Wuhan, China. Clin J Am Soc Nephrol. 2020;15(8):1139-1145. doi: 10.2215/CJN.04160320

32. Ma Y, Diao B, Lv X, et al. COVID-19 in hemodialysis (HD) patients: report from one HD center in Wuhan, China. medRxiv. Preprint posted June 17, 2020. doi: 10.1101/2020.02.24.20027201

33. Guillen E, Pineiro GJ, Revuelta I, et al. Case report of COVID-19 in a kidney transplant recipient: does immunosuppression alter the clinical presentation? Am J Transplant. 2020;20(7):1875-1878. doi: 10.1111/ajt.15874

34. Abbasinia M, Hormati A, Eshagh Hossaini SK, et al. Clinical manifestations of gastrointestinal symptoms in COVID-19 patients: an integrative review. Gastroenterol Nurs. 2021;44(1):E1-E10. doi: 10.1097/SGA.0000000000000584

35. Huang C, Wang Y, Li X, et al. Clinical features of patients infected with 2019 novel coronavirus in Wuhan, China. Lancet. 2020;395(10223):497-506. doi: 10.1016/S0140-6736(20)30183-5

36. Gold JAW, Wong KK, Szablewski CM, et al. Characteristics and clinical outcomes of adult patients hospitalized with COVID-19 - Georgia, March 2020. MMWR Morb Mortal Wkly Rep. 2020;69(18):545-550. doi: 10.15585/mmwr.mm6918e1

37. Manuel Jl. Racial/ethnic and gender disparities in health care use and access. Health Serv Res. 2018;53(3):1407-1429. doi: $10.1111 / 1475-6773.12705$

This article meets the Accreditation Council for Graduate Medical Education and the American Board of Medical Specialties Maintenance of Certification competencies for Patient Care, Medical Knowledge, and Practice-Based Learning and Improvement.

(C2021 by the author(s); licensee Ochsner Journal, Ochsner Clinic Foundation, New Orleans, LA. This article is an open (c) (i) access article distributed under the terms and conditions of the Creative Commons Attribution (CC BY) license (creativecommons.org/licenses/by/4.0/legalcode) that permits unrestricted use, distribution, and reproduction in any medium, provided the original author(s) and source are credited. 